prong, and if it gives a ring it has overtones and is not desirabie; but if it gives a dead sound, you will then probably get a pure, elear tone and the fork is of value in making these tests.

DR. G. McAulifFe, New York City-In dealing with eases of neurasthenia or allied conditions of nerve exhaustion, we should not hold the tuning fork too long in front of the ear. After resting the nerve if we will again approach the ear they will again appreciate the sound. If we do not do this we would get a shortened perception. Another point, in trying the Weber test-which I find the most unreliable one-is to place the fork underneath the mastoid, at the beginning of the sternomastoid. I have been able to get the proper response to the Weber test by this procedure.

Dr. S. Voorhees, Elmira, N. Y.-I would like to ask the Doctor if he does not find, for instance in labyrinthine disease, the higher tones are lost and the lower tones only recognized.

DR. B. A. Randall, Philadelphia-I think it is extremely important to get forks that are somewhere near what they purport to be. On testing on the kymographion the various forks furnished you will get some very peculiar results. It is very seldom that they will give the rapidity of vibration set down for them. Second, the value of the fork should be expressed in the frequency of the vibration and not by a symbol, which is so varying in its employment that the term "C fork" may represent at least three different octaves. It is better to employ the complete double vibration instead of the half vibration, as is done by most continental workers. Third, the blow struck should have some semblance to standardization, and in the tuning forks we should have some idea of the bulk of metal vibrating. Not too much of the metal should be in the handle, which should be long in high tuning forks, lest the fork be really heard largely through the air when resting on the head. If we are stating that a fork of, say, $2131 / 3$ d.v.s., is heard after a standard blow for so many seconds, let us have a standard that it has fallen its own height, that it is of such a length and such a weight. Then when men having different sized forks get different results we will have some clew as to why their results appear different when they are really the same. These things are extremely important; they are really fundamental to any understanding of the matter.

DR. William L. Ballenger, Chicago-In reply to Dr. Voorhees, as a general proposition there will be a loss of hearing for higher tones. The paper I left at home is a discussion of just such subjects as have been brought up in the discussion. It gives the technic of observation and testing and is intended as an answer to such objections. This paper only deals with the general principles.

\section{THE TREATMENT OF TRAUMATIC GANGRENE} OF THE EXTREMITIES.*

\section{VAN BUREN KNOTT, M.D.}

SIOUX CITY, IOWA.

In this brief paper it is my aim simply to call attention to a procedure which, in my experience, has proven of great utility in the management of these very troublesome and too often fatal cases. I shall not take up the pathology of traumatic gangrene, for with that you are all familiar, but shall confine myself to its treatment.

On referring to the literature we find all authorities agree that the only treatment of this class of cases consists in early amputation above the gangrenous area.

How often are we able to determine accurately the limits of the disease, particularly in those cases of rapidly spreading moist gangrene? Too often we are disappointed by the continuation of the process after amputation, and are compelled to reamputate much higher, in spite of which the patient often dies.

Again, if the gangrenous process does not involve the entire limb the flaps frequently slough, necessitating another operation and the sacrifice of what is too often

* Read before the Iowa Association of Railroad Surgeons, Oct. 16,1902 . most valuable tissue so far as the future usefulness of the part is concerned.

In other cases I have been convinced by subsequent events that in my effort to get well above the disease I have sacrificed tissue which might have been saved. In other words, I have amputated at a higher point than necessary. The occurrence of any of these conditions neither contributes to the welfare of the patient nor to the peace of mind of the surgeon, and we are all anxious to avoid them as completely as possible.

In casting about for the probable cause of the unsatisfactory course pursued by many of these cases I became convinced that it was the attempt to form flaps from tissue the vitality of which ia always seriously in question and the further impairment of that vitality by two procedures necessary to this method of operation. First, the dissection of the flaps; second, the introduction of sutures.

The dissection of the soft parts into suitable flaps necessarily interferes with its blood supply, which interference in the class of cases under consideration is often illy born and frequently resented by sloughing of the flaps ar the rapid extension of the gangrenous process up the limb. The introduction of sutures at this time has two distinct disadvantages. The first is the retention within the wound of infectious elements which may have traveled up between the muscle planes or along tendon sheaths to a higher point than we believe probable.

The second is the further interference with the flap nutrition by the suture tension which, no matter how carefully they may be placed, can not entirely be avoided. Believing the statements above made to be true, and that the bearing of these facts on the results secured in these cases was most important, I began about two years ago to treat all cases of traumatic gangrene of the extremities by a method which was entirely original and of which I have been able to find no mention in the medical literature at my disposal.

The procedure is as follows: Being confronted with a case of traumatic gangrene of an extremity, estimate as exactly as possible the line between the diseased and healthy soft parts, and having first under anesthesia made a most careful and complete disinfection and cleansing of the skin, puncturing all bullæ and removing all discharges, envelop the gangrenous area in a sterile towel up to the line selected and at this point make a circular amputation, cutting through soft tissues and bone at the same level. Ligate carefully all bleeding points, including none of the perivascular tissue in the bite of either the forceps or the ligature.

Leave the wound absolutely open, not introducing a single suture, and apply moist dressings of gauze saturated with salt solution. The dressings to be changed two to four times in twenty-four hours, as the circumstances of the particular case demand.

After seven to ten days, if the wound is perfectly clean and the condition of the patient favorable, the classical circular amputation may be made by dissecting up the flap already outlined and sawing the bone at the proper level. If for any reason the circular method may seem undesirable, any other procedure may be substituted, but in the class of cases under discussion a typical circular amputation will be found entirely satisfactory.

I will not burden you with a report of cases, but will simply state that I have employed this procedure four times, once in the upper third of the thigh, once in the middle third of the forearm and twice in the upper third of the leg with uniformly good results. 
CONCLUSIONS.

As my results by the old method can not be compared with these I have ventured to bring the procedure forward for consideration. Its advantages seem to me to be many and its disadvantages few.

1. By it we may speedily and with the minimum of shock remove from an enfeebled and exhausted patient the source of the infection, namely, the gangrenous tissue.

2. We may frequently make the amputation at a lower point than would be possible by the old method, because soft tissues whose vascular connections are left undisturbed are less apt to slough.

3. The freest possible drainage is provided for a sufficiently long time.

4. If the discase stops at the line first chosen no unnecessary sacrifice of tissue has been made, as the flaps have been defined at the lowest limit of safety and the bone would necessarily have to be sawn at the same point as at the second operation.

5. If the limits of the disease have not been placed sufficiently high the same procedure may be repeated with less danger to the patient than a typical reamputation.

6. Patients too weak and prostrated by sepsis to withstand a typical amputation may endure this much shorter procedure and be built up during the interval before the second operation is necessary.

I hope that use will be made of this method in the future management of these cases that its value may be more fully and satisfactorily proven or disproven.

\section{POISOPED WOUNDS BY THE IMPLEMENTS OF WARFARE.*}

LOUIS A. LA GARDE, M.D.

Majolr and surgeon, U. S. ARMiY.

Mr. President and Fellows of the College of Physicians: In the first place allow me to thank you for permitting me to address the honorable College of Physicians in the capacity of Mütter lecturer. In looking over the names of the distinguished men who have preceded me in this function, I admit that your invitation was accepted with a great deal of hesitancy. I accepted the charge because of a sense of duty to my department, and because it has been my good fortune to serve in most of the principal seats of learning in this country, and my observations have led me to the conclusion that there is a deep bond of fellowship between the military surgeon and his brethren in civil life that is largely cemented by a mutual love of all that is lofty and inspiring in the healing art. Your opportunities to set the pace as we advance in scientific medicine are superior, and your liberality in imparting great truths as we come to drink anew at the fountain of knowledge are well remembered. In return for the kind attention which you are wont to bestow on us when we resort among you, I beg of you to accept this effort as a mark of the gratitude which the military surgeon owes his civil confrère.

In discussing poisoned wounds by the implements of warfare it will appear difficult to separate them from infected wounds by these implements, and justly so. The terms are considered interchangeable in this instance so far as they relate to the transmission of micro-organisms, and it was considered expedient to retain the former term in order to conform to the old

* The Mütter Lecture, delivered at the College of Physlcians of Philadelphla, Dec. 2, 1902. idea of poisoned wounds from poisoned arrows, lances, etc.

\section{HISTORICAL.}

The poisonous nature of wounds by the implements of warfare-especially those from firearms-has been dwelt on by the majority of the older writers. Frequent reference is made to the subject by John de Vigo, and Ambroise Paré was so imbued with the venomous nature of such wounds by reason of the powder, that he was wont to "cauterize them with oil of elders scalding hot, mixed with a little treacle." His trepidations in one instance when his boiling oil mixture ran out are graphically told by his biographer. In the absence of anything more efficacious he was driven to the use of yolk of eggs, oil of roses and turpentine in the treatment of the remainder of the wounded. After a sleepless night spent in anxiety for those who had not been given the conventional treatment of the day, by hot burning oil, he found, to his astonishment, that they had suffered but little pain, and their wounds were without inflammation and swelling, having rested fairly well the night before; the others, on whom the boiling oil was used, were feverish, with great pain and swelling about the edges of their wounds. Thus disinfection by heat as he practiced it gave results rather confusing and conflicting.

On the other hand, Thomas Gale, in his treatise of wounds by gunshot, attempts to refute the erroneous notion of Ambroise Paré, Jerome Brunswicke, John de Vigo, Alfonse Terrius and others concerning the venomous nature of gunshot wounds.

It is seen, therefore, that, from the beginning, the belief in the septicity or asepticity of gunshot wounds was indulged in. As to the value of the heat of ignition, if any, to purify the missiles as they issue from firearms, we will speak later.

Poisoned wounds from the use of so-called sidearms, or more properly speaking, cutting and stabbing im. plements, like the spear, sword, arrow-heads, knives, javelins, etc., have a very interesting literature, dating back to the days of the Greeks and Romans. A practice that is abhorred to-day and classed among the most cowardly deeds in the list of crimes, seems to have been pretty generally adopted in ancient times. For a complete account of the use of poisoned arrows, including an outline of the toxicology of the substances employed for the purpose by the ancient peoples of Europe, we are indebted to Gustav Lagneau. He points out that specimens of arrows gathered from the later paleolithic periods give proof that the art of poisoning arrows was known to the inhabitants of prehistoric times. Arrows made of bone to serve the points of javelins, lances, etc., are to be found in numerous archeological collections, and they suggest by the method of preparation that they were designed to carry poisons. Their surfaces show furrows and grooves, disposed parallel to the sides; grooves are also found on the teeth or serrated margins, for the reception of the poisonous matter, similar to - what we find on the arrows of more modern periods.

The literature of historic times gives ample evidence of the use of poisoned arrows against man and beast. Thus Aristotle relates that the Celts in the hunt ùsed poison on their arrows which was called toxic. After wounding a deer, for instance, it was considered necessary to excise the seat of injury at once, in order to insure the safety of the meat as food and to prevent rapid decomposition. The Gauls, according to Pliny, dipped their arrows for the hunt in hellebore, which had the 